\title{
Saúde Reprodutiva e Sexual Masculina
}

em Francisco Morato, SP: o discurso de profissionais, gerentes e gestores de saúde Male Reproductive and Sexual Health in Francisco Morato: the discourse of health professionals, managers and

\section{administrators}

\section{Tiago Noel Ribeiro}

Mestre em Ciências.

Endereço: R. Oscar Freire, 2121, apto 203, Pinheiros, CEP 05409-011, São Paulo, SP, Brasil.

E-mail: tiagopsi®yahoo.com.br

\section{Resumo}

Este relato de pesquisa tem como objetivo mostrar como se configurava, em 2004, a atenção à saúde reprodutiva e sexual masculina no município de Francisco Morato, a partir do discurso de profissionais, gerentes e gestores de saúde. Foram entrevistados oito profissionais, cinco gerentes e três gestores de saúde, utilizando-se a entrevista como método de coleta de dados, e a análise temática para o seu tratamento. Mostramos que, a exemplo da tendência geral das ações em saúde pública no Brasil, a esterilização e o aconselhamento para a saúde sexual e reprodutiva eram calcados em uma visão biomédica. Existem, no entanto, iniciativas isoladas de atenção constituídas a partir de uma noção intuitiva das diferenças entre homens e mulheres na busca dos serviços de saúde. Foram propostos o fortalecimento e a criação de espaços coletivos para discutir os cuidados à saúde sexual e reprodutiva. 0 texto se encerra afirmando, ainda, a necessidade desses espaços para formulação e implementação de propostas que considerem os diversos perfis de morbimortalidade do município.

Palavras-chave: Masculinidades; Saúde Reprodutiva e Sexual; Sistema de Saúde; Atendimento integral à saúde. 


\section{Abstract}

This paper aims to show the situation of the male reproductive and sexual healthcare in the municipality of Francisco Morato in 2004, based on the discourse of health professionals, health managers and public health administrators. The participants in the investigation were eight health professionals, five health managers and three public health administrators. Interviews were used for data collection and thematic analysis was employed for data interpretation. We showed that, following the general trend of Brazilian public health actions, sterilization and sexual and reproductive health counseling used to be based on a biomedical viewpoint. Nevertheless, there are isolated care initiatives grounded on the intuitive notion that men and women are different in their search for healthcare services. The implementation of collective spaces and the strengthening of these spaces for the discussion of reproductive and sexual health are, therefore, proposed. In addition to that, it is stated in this paper that there is the need of formulation and implementation of further political proposals which take into account the different aspects involving morbidity and mortality in the municipality. Keywords: Gender identity; Sexual and reproductive health; Health System; Comprehensive health care; men.

\section{Introdução}

Este trabalho é resultado da dissertação desenvolvida no programa de pós-graduação de medicina preventiva da Faculdade de Medicina da Universidade de São Paulo (USP): Atenção à saúde sexual e reprodutiva masculina no município de Francisco Morato, cujo objetivo foi analisar, a partir do discurso de profissionais, gerentes e gestores de saúde em Francisco Morato, como se configura a atenção à saúde reprodutiva e sexual voltada aos homens no município, contextualizando a relevância da noção de gênero e do conceito de saúde reprodutiva e sexual e suas implicações para a atenção à saúde masculina. Dissertamos sobre os núcleos temáticos identificados no discurso dos entrevistados.

\section{Gênero e masculinidades}

Para compreender as diversas manifestações que diferenciam o masculino do feminino na realidade social, conferindo possibilidades de relacionamentos cotidianos distintos, a noção de gênero é fundamental, pois explicita alteridades sociais a partir das diferenças percebidas entre os sexos. Adquire contornos mais definidos a partir da década de 1980, quando estudiosos da área passam a concebê-lo como algo que diz respeito "a homens e mulheres", e não como "coisa de mulheres" (Gomariz, 1992; Connell, 1997; Garcia, 1998). Houve uma intensa produção teórica e empírica, tanto do movimento feminista como da teoria social, que procurou entender o fato concreto das diferenças cotidianas vividas por homens e mulheres. Nesse sentido, abriram-se possibilidades de estudos sobre as masculinidades e suas implicações no modo de viver dos homens, discutindo-se aspectos como trabalho, sexualidade, saúde, vida familiar etc.; pensando-se os homens a partir da sua especificidade enquanto construção mediada pela cultura, passando a ter cara, voz, corpo, ações etc., ou seja, enquanto sujeitos históricos.

No campo da política, o movimento feminista tem conseguido ocupar espaços importantes, o que aumenta suas possibilidades de viabilizar as ações diversas voltadas às mulheres. Com relação à teoria, setores do feminismo e da teoria social consideram que essa compreensão de gênero tem maior capacidade explicativa dos fenômenos sociais e de intervenção no cotidiano das pessoas. 0 enfoque que, segundo Couto e Schraiber (2005), incorpora os homens nas análises de gênero no campo da prevenção, da promoção e do 
cuidado em saúde tem sido utilizado, sobretudo, nos estudos de três temáticas: 1) morbi-mortalidade em homens; 2) violência e gênero; 3) saúde reprodutiva e sexual. Isso significa, por exemplo, nos estudos de morbi-mortalidade considerar os padrões gerais de socialização nos processos de saúde e adoecimento. Às discussões sobre violência, gênero e entre homens, agregou-se a compreensão de que sua emergência deve-se, em parte, aos padrões de masculinidade que valorizam comportamentos de exposição ao perigo, relações de dominação no espaço doméstico, sociabilidade e sexualidade, que ocorrem fundamentalmente no espaço público.

Nesse sentido, a incorporação da noção de gênero no campo de estudo das masculinidades possibilitou pensar essas questões considerando a relação entre as formas de ver e de agir no mundo de homens e mulheres como elementos que se intercambiam, complementam-se e se chocam, sendo necessários para uma compreensão da complexidade das manifestações das masculinidades.

O campo da saúde reprodutiva e sexual é uma área de destaque. Anteriormente, a temática privilegiava o olhar feminino sobre questões como o aborto e o planejamento familiar. $\mathrm{O}$ aumento da transmissão horizontal do HIV-Aids por via heterossexual evidenciou que essa questão estava sendo tratada de forma parcial, pois desconsiderava que, no campo da sexualidade no casamento, as mulheres têm pouco poder de negociação para o uso do preservativo (Garcia, 1998). Como a questão do HIV-Aids relaciona-se a outras temáticas, próprias do campo da saúde reprodutiva e sexual (planejamento familiar, conjugalidade etc.), houve a incorporação dos homens como sujeitos de pesquisa, extrapolando o estudo das masculinidades para outras questões relacionadas à saúde reprodutiva e sexual.

\section{Saúde reprodutiva e sexual}

O tema é profundamente vinculado à configuração dos atributos de gênero, à maneira como homens e mulheres vivenciam o cotidiano de forma diferente (Ávila e Gouveia, 1996). Refere--se, também, a uma discussão de políticas públicas para a construção de uma rede de serviços e atividades que considerem a reprodução e a sexualidade como direitos de homens e mulheres.

Na década de 1990, o termo ganha contornos mais definidos e maior capacidade explicativa. Sua definição parte do conceito de saúde da Organização Mundial de Saúde (OMS) para apresentar, de forma integrada, o conceito de saúde reprodutiva, a forma de assistência que lhe é apropriada e o conceito de saúde sexual. Segundo esse conceito, a saúde reprodutiva implica "[...] que a pessoa possa ter uma vida sexual segura e satisfatória, tendo a capacidade de reproduzir e a liberdade de decidir sobre quando e quantas vezes deve fazê-lo" (Melo, 2002, p. 8). Explicita-se que homens e mulheres têm direito a informações sobre métodos de planejamento familiar e de regulação da fecundidade eficientes, seguros, aceitáveis e compatíveis com sua renda. Além disso, coloca-se que se devem garantir condições adequadas para que as mulheres passem pela gestação "[...] e pelo parto, propiciando aos casais uma chance melhor de ter um filho sadio" (Melo, 2002, p. 9).

Podemos apresentar o entendimento de assistência à saúde como uma "constelação de métodos, técnicas e serviços que contribuem para a saúde e o bem-estar reprodutivo, prevenindo e resolvendo os problemas de saúde reprodutiva" (Melo, 2002, p. 9). A saúde sexual é considerada elemento importante na assistência à saúde reprodutiva, cujo objetivo é "[...] a melhoria da qualidade de vida e das relações pessoais, e não o mero aconselhamento e assistência relativos à reprodução e às doenças sexualmente transmissíveis" (Melo, 2002).

Em 1995, aconteceu em Beijing a Conferência da Mulher, que "[...] Confirmou os resultados da ICPD [Conferência Internacional Sobre População e Desenvolvimento do Cairo], porém suas metas enfatizaram ainda mais o enfoque de igualdade de gênero, reafirmando o foco nos direitos reprodutivos e humanos individuais" (Galvão, 1999, p.171).

Só recentemente os homens estão sendo incluídos na discussão conceitual da saúde reprodutiva. Sua inserção tem sido feita através dos aspectos relacionados à sexualidade no processo reprodutivo, tendo como resultado a ampliação da capacidade explicativa da definição de saúde reprodutiva a partir do conceito de direitos reprodutivos e sexuais, com o intuito de implementar e concretizar esses direitos nos serviços de saúde e nas políticas públicas (Galvão, 1999).

É posta em debate a junção ou disjunção dos direitos sexuais aos reprodutivos. Por um lado, a vivência da sexualidade e da reprodução pode dar-se ao mesmo tempo na vida das pessoas. Por outro lado, 
a sexualidade se refere a um conjunto de fenômenos (uso de preservativo, transmissão de DSTs etc.), e reprodução, a outro (esterilização, concepção etc.). A distinção pode ser tida como positiva, na medida em que permite pensar a complexidade dessas vivências em sua especificidade; e negativa, ao separar aspectos da vida que se constituem de forma integrada (Leal e Boff, 1996; Bandeira, 1999).

Essa discussão tem como aspecto importante a relação entre público e privado. As noções de sexualidade e de reprodução têm sido representadas como setores privados da vida social. Isso, porém, adquire diferentes contornos quando se pensa que a garantia de acesso a serviços de saúde, enquanto aspecto público da vida, é condição fundamental ao exercício dos direitos sexuais e reprodutivos.

O conceito de saúde reprodutiva e sexual é resultado de um processo de explicação dos fenômenos gerados pelas falhas das políticas públicas no âmbito da sexualidade, focadas exclusivamente na mulher e no controle de natalidade, anteriormente, à margem de uma compreensão dinâmica dos costumes e das crenças relativas à vida sexual e reprodutiva, bem como de seu processo de construção educacional na realidade cotidiana.

\section{0 municipio}

A maior parte dos serviços ofertados à população é municipalizada, com exceção do Hospital Estadual Professor Carlos da Silva Lacaz, administrado por uma Organização Social de Saúde ${ }^{1}$ (OSS) vinculada à Universidade de Santo Amaro. 90\% da população de Francisco Morato utiliza a programação das ações públicas de assistência à saúde.

A rede de serviços do município, em 2004, era gerida pelo Serviço de Assistência Médica de Francisco Morato (SAME), uma autarquia criada por lei municipal em julho de 1998. O Sistema de Saúde era organizado através da Estratégia de Saúde da Família (ESF) e do Programa de Agentes Comunitários (PACS), atingindo 91,09\% da população.

O município contava com 14 equipes, totalizando 95 agentes vinculados ao PSF, que atendiam 58,64\% da população. Outras três equipes com 57 agentes vinculados ao PACS atendiam 32,45\% da população.
O município dispunha de cinco prédios em Unidades Básicas de Saúde, a saber: 1) ambulatório de especialidades; 2) fisioterapia; 3) Centro Integrado de Saúde da Mulher (CISM) - Casa da Mulher; 4) pronto-atendimento e 5) Centro de Atenção Psicossocial (CAPS). A Vigilância Epidemiológica e a Sanitária tinham sede em uma edificação onde também se encontrava o SAME. As unidades de saúde, cuja gestão ficava a cargo da coordenação do PSF, eram divididas em doze setores.

\section{Material e Métodos}

Trabalhou-se com a pesquisa social, pois possibilita perceber de maneira sensível o movimento de construção das políticas públicas de saúde (Deslandes, 1997; Minayo, 2004), e utilizou-se o discurso como material de análise da pesquisa.

Utilizar a fala das pessoas implica em fazer um recorte da realidade na qual estão inseridas. E, para acessar o discurso dos sujeitos da pesquisa, utilizou-se como método a entrevista.

Utilizaram-se, como material de análise, entrevistas semiestruturadas com oito profissionais, cinco gerentes e três gestores, somando dezesseis sujeitos, divididos entre cinco homens e onze mulheres. Os profissionais foram considerados trabalhadores da saúde independente do regime de contratação: gerentes, todo e qualquer profissional de saúde que estivesse em algum cargo de gestão do serviço de saúde; e gestores, os gerentes dos níveis centrais na Secretaria de Saúde do município.

As entrevistas foram gravadas em fita K7 no local de trabalho dos entrevistados, com duração média de 30 minutos, e transcritas pelo próprio pesquisador. As entrevistas apenas começaram após a leitura comentada e a assinatura do TLCE (Termo de Consentimento Livre e Esclarecido) por parte dos sujeitos e do entrevistador, sendo que cada um ficou com uma via do documento. O projeto de pesquisa foi aprovado mediante análise do Comitê de Ética do Instituto de Saúde (CEPIS), protocolo oo8/o4, e pelo Comitê de Ética para Análise de Projetos de Pesquisa (CAPPesq) do Hospital das Clínicas da Faculdade de Medicina de Universidade de São Paulo (HC-FMUSP), protocolo 1044/05.

1 Inaugurada em 2 março de 2004. 


\section{Os entrevistados}

Entre os profissionais, três têm ensino superior completo; dois possuem título de especialista; dois têm curso técnico; e um, o ensino médio. Entre os gerentes, dois têm o ensino médio; um, o ensino superior completo; um tem o curso técnico; e de um deles essa informação não foi extraída. Entre os gestores, dois têm ensino superior completo com especialização; e um tem ensino superior completo.

A maior parte dos sujeitos (oito) trabalhava há mais de sete anos e menos de dez anos na saúde; cinco, há mais de dez anos e menos de trinta anos; e três sujeitos trabalhavam há mais de quatro anos e menos de sete anos.

Com relação ao tempo de trabalho no município, oito sujeitos estavam entre quatro e sete anos; cinco sujeitos, entre nove meses e quatro anos. Entre os profissionais, a maioria (quatro) está na faixa entre nove meses e quatro anos. Entre os gestores, a maioria (quatro) está na faixa entre quatro anos e sete anos; e entre os gestores, três trabalham no município entre quatro e sete anos.

\section{Sexo, Sexualidade e Preservativos}

As ações do sistema de saúde visavam tanto a adolescentes quanto a homens adultos. Os principais aspectos emergentes do discurso dos entrevistados são: 1. Prevenção: aconselhamento para saúde sexual; 2. Prevenção: distribuição e uso do preservativo; 3 . Atenção às DSTs.

\section{Prevenção: aconselhamento para saúde sexual}

A prevenção é o primeiro aspecto a emergir do discurso do conjunto dos profissionais e seu foco de atuação é o aconselhamento para saúde sexual e o uso do preservativo. As atividades de aconselhamento acontecem prioritariamente em ambiente escolar para adolescentes. São palestras mensais realizadas por profissionais da atenção básica de uma UBS, nas quais são apresentadas fotos de DSTs e realiza-se uma conversa sobre as dúvidas quanto a assuntos referentes à sexualidade num âmbito biológico (como as doenças relacionadas à prática sexual e os métodos para evitá-las).

Uma enfermeira e uma agente comunitária de saúde encaram essas atividades como primordiais por acontecerem em momento e local privilegiados da vida. Essas entrevistadas consideram que a ampliação desse trabalho nas escolas e nas unidades de saúde poderia fazer com que a discussão sobre sexualidade atingisse um contingente expressivo de adolescentes residentes no município.

$\mathrm{O}$ aconselhamento apresentou-se como uma atividade pouco estruturada, construída a partir da perspectiva dos profissionais de saúde e não integrada a uma programação de atividades educativas regulares voltadas para essa questão. Uma profissional apresenta os limites e as possibilidades desta atividade:

A juventude principalmente tinha que ter um apoio, um trabalho mais detalhado sobre DST porque não tem, não éfeito. Enas escolas - e eu trabalho nas escolas também -, quando a gente chega que vai falar pra eles, mesmo que um profissional tenha passado por lá mês passado, você chega hoje pra eles e eles não sabem de nada, eles não entende, acham horror tudo que você mostra. Porque você leva foto de uma determinada doença "é um absurdo" (Agente Comunitária de Saúde, UBS).

Ayres e França Junior (2000) entendem a sexualidade como um aspecto importante da vida dos adolescentes por ser parte da socialização, com implicações na construção da subjetividade e identidade. Segundo os autores, dois aspectos dessa vivência têm particular ligação com o setor saúde: a procriação e a vulnerabilidade às doenças sexualmente transmissíveis (DSTs). Os autores propõem que o objetivo de um programa de atenção à saúde do adolescente seja "apoiar a vivência da sexualidade adolescente" (p. 73) e que um dos tipos de ações seja "fornecer informações e espaços de reflexão sobre aspectos físicos, sociais e culturais julgados relevantes, pelos adolescentes e profissionais, para uma sexualidade mais livre e prazerosa" (p.73). Pirotta e colaboradores (2006) apontam a necessidade de uma parceria entre educação e saúde para tratamento integral ao adolescente e ao jovem.

Pirotta (2006), acerca das atividades realizadas nas unidades de saúde com a juventude, percebe um enfoque informativo, no qual há pouca preocupação com a preparação pedagógica destas. Além disso, é privilegiado o ponto de vista do profissional, segundo o qual é dada atenção aos aspectos biológicos do exercício da sexualidade. Nesse sentido, o adolescente parece ser entendido como incapaz de determinar o que entende como relevante para as ações de prevenção em saúde na 
escola. As colocações da ACS evidenciam uma prática semelhante à criticada por Pirotta (2006).

Uma Agente Comunitária de Saúde (ACS), que realiza visitas em domicílios habitados exclusivamente por homens, relatou outra ação de aconselhamento durante as quais os moradores demandam informação sobre sexualidade e HIV. É interessante perceber que os homens se sentem à vontade para colocar dúvidas dessa natureza em um espaço vinculado ao feminino, o espaço doméstico; na percepção da ACS, contudo, apenas se houver a presença de outros homens.

\section{Prevenção: distribuição e uso do preservativo}

Em quase todos os ambientes (domicílios, unidades de saúde e escolas) onde ocorrem ações de prevenção, o emprego da palavra preservativo aparece vinculado às DSTs. Extrairam-se das falas dos entrevistados três núcleos temáticos em que o preservativo (ou sua falta) aparece na assistência. 0 primeiro: quando a juventude vai à unidade de saúde pedir a realização de exames para verificar a infecção por HIV. Essa solicitação permite-nos pensar que falta o uso do preservativo nesse grupo populacional:

O que eles mais querem saber é se eles podem doar sangue... se eles tiveram algum tipo de relação sem preservativo, eles querem que peça o exame do HIV... é mais esse tipo de coisa... é bem diferente o jovem (Médico, UBS).

Esse uso frequente da unidade de saúde parece ter relação com as deficiências relacionadas ao trabalho de aconselhamento realizado nas escolas. Indica uma limitação na constituição de práticas preventivas relativas ao sexo seguro pelos jovens, e, além disso, o dito aconselhamento parece reforçar o espaço das unidades de saúde como local no qual prioritariamente se realizam atividades curativas. Por outro lado, a procura dos adolescentes pelos serviços de saúde, quando da suspeita de ter contraído DST/Aids via sexo desprotegido, parece apontar para o êxito da ação preventiva nas escolas. Pode-se depreender disso que eles entendem o espaço da unidade de saúde como próprio para o cuidado das questões ligadas à sexualidade.

O segundo núcleo temático é a negociação para o uso da camisinha pelos casais. Uma profissional colocou a ideia de que os homens têm mais autonomia para decidir sobre uso do condom do que as mulheres. A dita entrevistada considerou importante a realização de um trabalho com os homens para discutir suas relações afetivas e sexuais.

As questões de sexo seguro, planejamentos, porque você tem que pegar o homem também... porque ele [influi] também na relação, as vezes ele tem mais autonomia do que a própria mulher... (Enfermeira, UBS).

A percepção de que os homens determinam predominantemente o método contraceptivo utilizado pelo casal é consoante com estudos realizados por Duarte (1998), Marchi e colaboradores (2003), Duarte e colaboradores (2003), Espírito-Santo e Tavares Neto (2004). Entretanto, a ideia mencionada na fala da enfermeira não se configura enquanto atividade ou percepção corrente nos serviços. A discussão com homens sobre relações afetivas e sexuais pode servir como instrumento para a transferência de poder para as mulheres. Como Vilella (1998), acreditamos que isso se configure apenas como um primeiro momento para gerar condições de negociação equânime pelo casal.

Autores como Arilha (1998), Nascimento (s.d), Figueroa-Perea (1998) e Olavarria (2003) enfatizam a importância do trabalho em saúde sexual com os homens para além da concepção de que estes facilitam ou dificultam o uso da camisinha nas relações heterossexuais como método de proteção das DST/Aids. Eles argumentam a necessidade de romper com a vinculação de homens com a sexualidade e das mulheres com a reprodução, pois a pretensa autonomia masculina na prática sexual esconde práticas sexuais prejudiciais à sua saúde e de suas companheiras.

o terceiro núcleo temático refere-se ao uso do preservativo após a esterilização masculina. Agentes comunitárias de saúde, médicos e enfermeiras envolvidos no processo de planejamento familiar relatam que os homens recebem esclarecimentos quanto às características do procedimento cirúrgico, especialmente quanto aos aspectos relativos à preservação da ereção, da ejaculação e do prazer. Os entrevistados percebem que os homens equiparam vasectomia e castração, o que diminui a procura pela cirurgia de esterilização. Viveros e colaboradores (1998) e Keijzer (2003) indicam que a impossibilidade de gerar filhos provoca o questionamento da identidade masculina calcada na demonstração pública de sua virilidade.

Os entrevistados percebem que os homens vinculam preservativo e reprodução, por isso recomendam 
enfaticamente o uso do condom como forma de evitar DSTs. Acreditam que, com a realização da esterilização, os homens aumentam sua atividade sexual desprotegida com diversas parceiras, pois o ato sexual passa a ser definitivamente desvinculado da atividade reprodutiva.

A gente deixa bem claro "Vai fazer a vasectomia, mas vai ter que continuar a prevenir"... que a vasectomia é só para não ter filho, agora DST não tem como... se não usar camisinha pega mesmo... (Agente Comunitária de Saúde, UBS).

\section{Atenção às DSTs}

Esse próximo aspecto discute a presença e a participação dos homens em diversos espaços de atenção à saúde, a partir da apresentação de duas intervenções com objetivos curativos. A primeira é realizada em uma Unidade de Saúde da Família (USF), na qual é montado um esquema de atendimento a homens e mulheres que buscam a unidade de saúde com queixas relativas às DSTs. Caso a queixa dos usuários indique uma DST, visando à preservação da sua intimidade, as ACSs agendam a consulta e comunicam à equipe. Preferencialmente, os homens são atendidos por médicos do sexo masculino.

Durante a consulta, caso seja necessário o encaminhamento para um especialista, este é feito prontamente. Segundo uma enfermeira, a população na faixa dos 20 anos foi beneficiada por essa forma de atenção às DSTs.

Essa estratégia reflete a concepção de que a sexualidade é um assunto privado que envolve diversas questões, com abordagem delicada para ambos os sexos. Ela acolhe os homens com queixas de DSTs, garantindo que o motivo da procura pela unidade de saúde seja mantido em sigilo. Além disso, o fato de o profissional ser do sexo masculino possibilita, segundo o médico dessa UBS, que os homens percebam que os problemas serão melhor compreendidos. Em um contexto no qual os usuários do sexo masculino entendem as unidades como espaço feminino, essa foi a forma encontrada pela equipe para tratar as DSTs.

Pesquisador: Como você acolhe a queixa desses homens com DST?

Entrevistado: Quem informa é o agente de saúde, o agente de saúde conversa com a gente, a gente bola um horário que eles possam tá vindo aqui... por que eles chegarem na recepção e fala que tem um probleminha nesse sentido... tem uma fila atrás escutando o que ele tá falando, e ele não fala... (Médico, UBS).

Acerca da preferência dada pelo serviço de que os homens sejam atendidos por médicos do mesmo sexo, Woods e colaboradores (2002), em pesquisa realizada com general practitioners na Austrália, verificaram que os profissionais homens tendem a realizar consultas mais curtas. Pode-se pensar, a partir desse achado, que essa escolha do município seja um fato positivo, pois vai ao encontro das expectativas dos homens por atendimentos mais rápidos e diretos.

A outra ação curativa acontece no Pronto-Socorro (PS). Nesse nível de atenção, dada a própria característica de espaço e funcionamento, ao contrário da USF, os homens são diretos ao falar na recepção sobre seu problema de saúde.

Pesquisador: Como os homens apresentam para você uma questão de saúde relacionada à DST?

Entrevistada: Dificilmente têm vergonha... (Gerente, sexo feminino, Pronto Socorro).

Essas colocações indicam que há espaços nos quais os homens se sentem mais seguros para apresentar problemas de saúde referentes à sexualidade. Woods e colaboradores (2003) elencam alguns elementos que ajudam a compreender a utilização dos serviços de saúde pelos homens. Nesse trabalho, o tempo de espera pelo atendimento e o desconforto nos serviços de atenção primária configuram-se como questões que levam os homens a buscar serviços de urgência e emergência. Além disso, os autores colocam a ideia de que o cuidado com a saúde não se configura como aspecto positivo na construção da identidade masculina, ideias corroboradas por Keijzer (2003), Vigoya (2001), Telleria (2003), Figueiredo (2005), Schraiber (2005), Schraiber e colaboradores (2005).

A estratégia executada na unidade básica de saúde, bem como o olhar da profissional do pronto-socorro, corrobora a pouca familiaridade dos homens com o espaço da UBS. Entretanto, não existe uma política municipal voltada a esse problema, enfrentado apenas pela referida USF. Estratégias semelhantes, conforme discute Figueiredo (2005), produzem resultados interessantes na forma como os homens passam a perceber o serviço de saúde primário e o cuidado à saúde em geral. 


\section{Esterilização Masculina}

Este tópico tem como questão central a cirurgia de esterilização masculina a partir de categorias temáticas geradas pela análise do discurso dos entrevistados. Tem-se como eixo a realização da vasectomia no município, organizada do seguinte modo: Público-alvo da esterilização; Do planejamento familiar à vasectomia; Motivos para a realização da vasectomia.

\section{Público-alvo da Esterilização}

O público-alvo da esterilização, à época das entrevistas, eram os homens. Essa população, na percepção dos entrevistados, tem como características ser pobre; ter muitos filhos; ser, na sua maioria, constituída por migrantes dos estados do Nordeste brasileiro; e estar na faixa etária de 40 anos.

De modo geral, a pobreza aparece associada à uma capacidade reduzida de compreensão de questões referentes aos métodos de controle da natalidade. Os entrevistados, contudo, não problematizaram sua própria ação educativa frente à população atendida. Outras características são: baixo autocuidado em termos de higiene pessoal, levando a uma ação, após a vasectomia, destinada a garantir uma recuperação sem infecções. Essa ação consiste na administração de um "antibiótico profilático" (Médico, atenção secundária), pois não se sabe “[...] se eles [homens] vão ter um asseio adequado" (idem). Segundo ele, essa população tem um acesso restrito ao saneamento básico e poucas práticas de autocuidado.

Ser nordestino relaciona-se a maiores restrições na utilização de métodos contraceptivos e a um número grande de filhos. Eles são percebidos pelos profissionais, gerentes e gestores, como homens machistas e não monogâmicos.

Tem a questão social de Francisco Morato, que é predominantemente de migrantes nordestinos, tem. Uma sociedade que é machista, que não é monogâmica, que tem mais de uma mulher, que tem uma dificuldade de usar preservativo, que acha que fazer uma cirurgia de vasectomia vai deixar de ser homem (Gestor).

Viveros (1998), Viveros e colaboradores (1998) e Keijzer (2003), entre outros autores, apontam que a vasectomia, nesse contexto cultural, é entendida como castração. Portella e colaboradores (2004) perceberam diferenças entre homens da Zona da Mata de Pernambuco e dos municípios do Rio de Janeiro e São Paulo, em que os primeiros seguem uma matriz tradicional de masculinidade e os homens da região sudeste “[...] articulam elementos tradicionais e inovadores no que toca aos padrões de gênero, embora os homens mais velhos compartilhem muitos dos pontos de vista dos pernambucanos" (Portella e col., 2004, p.1).

Portella e colaboradores (2004) colocam que os homens migrantes advindos do Nordeste brasileiro, na faixa etária de 40 anos, tendem a seguir o dito modelo tradicional de masculinidade, no qual a paternidade é tida como prova de hombridade. Esse achado é consoante com a percepção dos entrevistados acerca dos homens nordestinos, característica do público-alvo da vasectomia, que dificultam, segundo o supracitado gestor, a adesão dos homens à cirurgia.

\section{Do planejamento familiar à vasectomia}

Segundo relato de profissionais, gerentes e gestores, o planejamento familiar ocorre em todas as unidades de atenção à saúde básica, tendo sido separado em três momentos: o processo decisório para a cirurgia, o pré e o pós-cirúrgico.

\section{0 processo decisório para a cirurgia}

Os entrevistados apresentam algumas formas de os homens frequentarem os grupos de planejamento familiar. Uma delas ocorre durante o pré-natal, no qual os profissionais de saúde sugerem aos usuários que se integrem ao planejamento familiar². Outra, no cotidiano da assistência à saúde (níveis primário e secundário), com homens e mulheres sendo chamados a se integrarem no processo de planejamento familiar. Uma ACS afirmou que homens já esterilizados indicam o procedimento cirúrgico a outros, levando ao aumento da procura pelos grupos.

As informações indicam que os homens têm se preocupado mais com a saúde de sua companheira e de seu filho, mudando de uma paternidade ausente para uma presente. Os homens estão frequentando mais as unidades de saúde, possibilitando o convite dos profissionais para os grupos de planejamento familiar. Já a indicação de homens esterilizados a outros é, segundo 
Marchi e colaboradores (2003), uma fonte de informação frequentemente buscada para o esclarecimento acerca do método.

Os entrevistados relataram que a implantação do Programa de Saúde da Família (PSF) é um fator importante para uma maior participação dos usuários homens nas ações propostas pelo sistema de saúde.

Antes era mais difícil... depois do PSF é que a maioria [dos homens] tá vindo... pra acompanhara mulher ou filho... mas antes nem pra isso eles tavam vindo... (Agente Comunitária de Saúde, UBS).

No processo de planejamento familiar, os usuários participam de grupos educativos com psicólogos, assistentes sociais e enfermeiros para conhecer os métodos e decidir qual método contraceptivo os casais utilizarão. Os entrevistados relatam que esses grupos são mais frequentados por mulheres, havendo muitas desistências.

\section{o processo pré-cirúrgico}

Após a decisão pela vasectomia e o consentimento escrito da parceira quanto à cirurgia, os procedimentos são realizados na Santa Casa do município. Sentados em grupos de cinco, os homens aguardam em frente à sala do cirurgião para a vasectomia. Eles já se submeteram aos exames para hipertensão, diabetes e espermograma, além de ter realizado a ciclotomia ("raspar os pelinhos").

Segundo a gerente responsável pela unidade hospitalar, é designado um auxiliar de enfermagem homem, de preferência "homem mesmo" (sic) para acompanhá-los na espera da cirurgia. Antes do procedimento realiza-se uma breve reunião, na qual o profissional reitera a impossibilidade de ter filhos após a cirurgia e a alternativa pela desistência, enfatizando que o método não impede a infecção por DSTs/Aids.

No caso da vasectomia, o médico já é do sexo masculino, eu já deixo um funcionário do sexo masculino... porque eles se sentem constrangidos de ficar uma mulher lá dentro, quem é que não se sente, ele não tá doente... porque quando ele tá doente fica um pouco mais debilitado, acaba que nem faz tanta questão... mesmo assim se o paciente questionare quiser alguém do sexo masculino, não é para opor, que vá alguém do sexo masculino lá... então na vasectomia, como eles tão conscientes, tão todos ativos, brincando o tempo inteiro, conversando eu mesmo faço essa colocação, eu só deixo homem, homem mesmo pra atender o sexo masculino na vasectomia... (Gerente, sexo feminino, Santa Casa).

\section{0 processo pós-cirúrgico}

Logo após a cirurgia, o grupo é novamente reunido e orientado no hospital a não ter atividade sexual no período de uma semana, após o qual o homem deve usar camisinha e a mulher, anticoncepcional oral. Após o período em que este homem tenha vinte ejaculações, precisa submeter-se ao espermograma para verificar se há produção de espermatozoides.

\section{Motivos para a realização da vasectomia}

Os profissionais apresentaram mais razões favoráveis que contrárias à cirurgia: sua realização é mais rápida e mais simples que a laqueadura; é uma cirurgia local e de alta imediata. Seu caráter definitivo foi a única justificativa apontada para a não realização.

Percebe-se que há um privilégio das vantagens técnicas para a realização da vasectomia. Viveros e colaboradores (1998) criticam essa visão biomédica da vasectomia. Os autores colocam que, em um contexto no qual a decisão pelo método contraceptivo se dá na relação entre profissionais e usuários, as motivações subjetivas dos envolvidos e os temores dos homens deveriam ser considerados no esclarecimento acerca da vasectomia.

Ao relacionar os motivos técnicos que justificam a realização da vasectomia às ações programadas de planejamento familiar, verifica-se que essa política tem sido vista com satisfação pelos profissionais, gerentes e gestores. Eles relatam que as cirurgias de vasectomia têm contribuído para vencer o preconceito em torno da participação dos homens no planejamento familiar.

$\varepsilon$ isso tá mudando, se você vir num dia que nós temos cirurgia, vaiver os homens vindo fazer cirurgia de vasectomia e saindo satisfeitos e indicando para outros homens. Então isso éuma mudança de cultura, de sociedade, de perfil, de visão de saúde pública (Gestor do nível central, sexo masculino).

Machi e colaboradores (2003) fazem uma reflexão sobre a implicação dos homens nos métodos de contracepção. Eles colocam a necessidade de permitir, para homens e mulheres, a escolha livre e informada sobre um método contraceptivo, implicando dispor de várias opções. Consideram importante entender as motivações e expectativas masculinas sobre a anticoncepção. 


\section{Considerações Finais}

O lugar-comum entre os entrevistados é o discurso de que os homens usam os serviços de saúde de forma seletiva, de acordo com os modos de representar sua identidade de gênero, o que implica numa procura menos frequente que a das mulheres, sobretudo na atenção básica. Os homens buscam os serviços, mas apenas quando ocorre a intensificação de algum problema de saúde; e participam de alguns programas e serviços disponibilizados para si próprios e para a família, quando incentivados.

Sexualidade e reprodução são percebidas a partir de uma visão biomédica, focada no indivíduo e em aspectos biológicos do sujeito. Sua superação implica em uma articulação entre a realidade cultural e demográfica do município e a criação de estratégias para o aumento da participação masculina (suas preferências na busca pela atenção à saúde e reações no atendimento às DSTs, bem como o processo de planejamento familiar).

Essa investigação também revelou que, ao falar das diferenças de gênero, os entrevistados puderam pensar acerca da sua prática. Depreende-se disso a importância de fortalecer os espaços para o exercício crítico da realidade e a circulação das informações sobre a percepção dos atores envolvidos na atenção à saúde, criando conhecimento sobre o modo de viver de homens, mulheres, crianças, idosos, orientação sexual etc. para intervenções que considerem aspectos geográficos, laborais, geracionais, raciais e de gênero. Isso implica na aquisição de concepções e práticas pedagógicas participativas, rompendo com paradigmas baseados em valores tradicionais e preconceitos.

\section{Referências}

ARILHA, M. Homens: entre a "zoeira" e a "responsabilidade”. In: ARILHA, M.; UNBEHAUM, S. G.; MEDRADO, B. (Orgs.). Homens e masculinidades: outras palavras. São Paulo: ECOS/Ed.34, 1998. p. 51-77.

ÁVILA, M. B; GOUVEIA, T. Notas sobre direitos reprodutivos e direitos sexuais. In: PARKER, R.; BARBOSA, M. R (Orgs.). Sexualidades brasileiras. Rio de Janeiro: Relume Dumará, 1996. p. 16o-72.
AYRES, J. R. C. M.; FRANÇA JUNIOR, I. Saúde do adolecente. In: SCHRAIBER, L. B.; NEMES, M. I. B.; MENDES-GONÇALVES, R. B. Saúde do adulto: programas e ações na unidade básica. 2. ed. São Paulo: Hucitec, 200o. p. 66-85. (Saúde em debate, 96; Série didática, 3)

BANDEIRA, L. Relações de gênero, corpo e sexualidade. In: GALVÃO, L.; DIAZ, J. (Orgs.). Saúde sexual e reprodutiva no Brasil. São Paulo: Hucitec/ Population Council, 1999. p. 18o-97. (Saúde em debate, 125)

CONNELL, R. W. La organización social de la masculinidad. Santiago: Isis Internacional, 1997. (Ediciones de las mujeres, 24).

COUTO, M. T.; SCHRAIBER, L. B. Homens, saúde e violência: novas questões de gênero no campo da saúde coletiva. In: MINAYO, M. C. S. (Org.). Críticas e atuantes: ciências sociais e humanas em saúde na América Latina. Rio de Janeiro: Fiocruz, 2005. p. 687-706.

DESLANDES, S. F. Concepções em pesquisa social: articulações com o campo da avaliação em serviços de saúde. Cadernos de Saúde Pública, Rio de Janeiro, v. 13, n. 1, p. 103-7, jan./mar. 1997.

DUARTE, G. A. Perspectiva masculina quanto a métodos contraceptivos. Cadernos de Saúde Pública, Rio de Janeiro, v. 14, supl. 1, p. 125-30, 1998.

DUARTE, G. A., et al. Participação masculina no uso de métodos contraceptivos. Cadernos de Saúde Pública, Rio de Janeiro, v. 19, n. 1, p. 207-16, jan./fev. 2003.

ESPÍRITO-SANTO, D. C.; TAVARES NETO, J. A visão masculina sobre métodos contraceptivos em uma comunidade rural da Bahia, Brasil. Cadernos de Saúde Pública, Rio de Janeiro, v. 20, n. 2, p.526-9, mar./abr. 2004.

FIGUEIREDO, W. Assistência à saúde dos homens: um desafio para os serviços de saúde de atenção primária. Ciência \& Saúde Coletiva, Rio de Janeiro, v. 10, n. 1, p. 105-9, jan./mar. 2005.

FIGUEROA-PEREA, J. G. Algunos elementos para interpretar la presencia de los varones en los procesos de salud reproductiva. Caderno de Saúde Pública, Rio de Janeiro, v. 14, supl. 1, p. 87-96, 1998. 
GALVÃO, L. Saúde sexual e reprodutiva, saúde da mulher e saúde materna: a evolução dos conceitos no mundo e no Brasil. In: GALVÃO, L.; DIAZ, J. (Orgs.). Saúde sexual e reprodutiva no Brasil. São Paulo: Hucitec/Population Council, 1999. p. 165-79. (Saúde em debate, 125)

GARCIA, S. M. Conhecer os homens a partir do gênero e para além do gênero. In: ARILHA, M.; UNBEHAUM, S. G..; MEDRADO, B. (Orgs.). Homens e masculinidades: outras palavras. São Paulo: Ed. 34, 1998. p. 31-50.

GOMÁRIZ, E. Los estudios de género y sus fuentes epistemológicas: periodizaçión y perspectivas. Santiago: Isis International, 1992. (Ediciones de las mujeres, 17)

KEIJZER, B. Hasta donde el cuerpo aguante: gênero, cuerpo y salud masculina. In: CÁCERES, C., et al. (Coords.). La salud como derecho ciudadano: perspectivas y propuestas desde América Latina. Lima: Faculdade de Saúde Pública y Administração da Universidade Peruana Cayetano Herida, 2003. p. 137-52.

LEAL, O. F.; BOFF, A. M. Insultos, queixas, sedução e sexualidade: fragmentos de identidade masculina em uma perspectiva relacional. In: PARKER, R.; BARBOSA, R. M. (Orgs). Sexualidades brasileiras. Rio de Janeiro: Relume Dumará, 1996. p. 119-35.

MARCHI, N. M., et al. Opção pela vasectomia e relações de gênero. Cadernos de Saúde Pública, Rio de Janeiro, v. 19, n. 4, p. 1017-27, jul./ago. 2003.

MELO, M. Ciência, sexualidade e reprodução humana: como ensinar? 2002. Disponível em: <http:// cidade.usp.br/educar2002/modo8/paper\%2omelo. doc.> Acesso em: 5 ago. 2004.

MINAYO, M. C. O desafio do conhecimento: Pesquisa qualitativa em saúde. 8. ed. São Paulo: Hucitec, 2004. (Saúde em debate, 46)

NASCIMENTO, P. O sexo dos homens:

vulnerabilidade e prevenção às DST/AIDS. s.d. Disponível em: <http://www.papai.org.br/admin/ biblioteca/arquivos/20070301124959.pdf?PHPSES $\mathrm{SID}=\mathrm{f} 58$ geза $4 \mathrm{dcf} 6 \mathrm{~d} 8743$ ed169odeeo $77 \mathrm{fc} 8>$. Acesso em: 28 abr. 2004 .
OLAVARRIA, J. Derechos sexuales y reproductivos $y$ los hombres. 2003. Disponível em: <http://www. flacso.cl/flacso/biblos.php?cade=619>. Acesso em: 20 out. 2005 .

PIROTTA, K. C. M. A construção sócio-histórica da adolescência e a políticas públicas. BIS - Boletim do Instituto de Saúde, São Paulo, n. 4o, p. 2-6, dez. 2006. PIROTTA, K. C. M., et al. Educação sexual na escola e direitos sexuais e reprodutivos. BIS - Boletim do Instituto de Saúde, São Paulo, n. 40, p. 16-8, dez. 2006.

PORTELLA, A. P., et al. Sexualidade e reprodução: perspectivas de homens e mulheres. IPAS Brasil, jan.2004. Disponível em: <http://www.ipas.org.br/ revista/jano4.html>. Acesso em: 16 mar.2004.

SCHRAIBER, L. B. Eqüidade de gênero e saúde: o cotidiano das práticas no programa de saúde da família do Recife. In: VILLELA, W.; MONTEIRO, S. (Orgs.). Gênero e saúde: programa saúde da família em questão. Rio de Janeiro: Abrasco; Brasília: UNFPA, 2005. p. 39-61.

SCHRAIBER, L. B.; GOMES, R.; COUTO, M. T. Homens e saúde na pauta da saúde coletiva. Ciência \& Saúde Coletiva, Rio de Janeiro, v. 10, n. 1, p. 7-17, jan./mar. 2005.

TELLERÍA, J. M. Reflexiones autocríticas acerca de una investigación sobre la busqueda de atención y demandas en salud de hombres en Santa Cruz de la Siera-Bolivia. In: CÁCERES, C., et al. (Coords.). La salud como derecho ciudadano: perspectivas y propuestas desde América Latina. Lima: Faculdad de Salud Pública y Administración de la Universidad Puruana Cayetano Herida, 2003. p. 165-72.

VIGOYA, M. V.. Contemporary Latin American perspectives on masculinity. Men and Masculinities, New York, v. 3, n. 3, p. 237-6o, Jan. 2001.

VILLELA, W. Homem que é homem também pega AIDS? In: ARILHA, M.; UNBEHAUM, S.; MEDRADO, B. Homens e masculinidades: outras palavras. São Paulo: ECOS/Ed. 34, 1998. p. 129-42.

VIVEROS, M. Orden corporal y esterilización masculina. Horizontes Antropológicos, Porto Alegre, v. 4, n. 9, p. 145-170, out 1998. 
VIVEROS, M.; GOMEZ, F.; OTERRO, E. Las

representaciones sociales sobre la esterilización masculina. El punto de vista de los orientadores del servicio de vasectomía en la Clínica del Hombre, en Bogotá, Colombia. Cadernos de Saúde Pública, Rio de Janeiro, v. 14, supl. 1, p. 97-103, 1998.

WOODS, M.; MACDONALD, J.; CAMPBELL, M.

General practitioners and men's health: perceptions and practicalities [on-line]. 2002. Disponível em: <http://menshealth.uws.edu.au/documents/ GP\%2oConf\%2oPaper.pdf >. Acesso em: 28 abr. 2008. 